\title{
RETRACTED ARTICLE: Towards a Descriptive Model of Humanitarian Assistance in Complex Emergencies
}

\author{
Kubilay Kaptan ${ }^{1,2}$
}

Published online: 21 December 2015

(C) International Society for Third-Sector Research and The Johns Hopkins University 2015

A careful analysis of the paper entitled "Towards a Descriptive Model of Humanitarian Assistance in Complex Emergencies" published online has led to the conclusion that this contribution shows extensive similarities with another paper authored by Georg Frerks and Dorothea Hilhorst entitled "Evaluation of Humanitarian Assistance in Emergency Situations" published in 2002 as UNHCR Working Paper No. 56. Large sections of the text were reproduced without any form of authorization. The author listed had no involvement with this article and was never consulted prior to its publication.

Given the duplication of content described above, the Voluntas article in question is being retracted at the request of the editors. We apologize to the readers that this was not detected during the submission and review process.

Voluntas prides itself on the publication of high-quality papers and accepts only original contributions.

Electronic supplementary material The online version of this article (doi:10.1007/s11266-015-9670-3) contains supplementary material, which is available to authorized users.

Kubilay Kaptan

kaptankubilay@gmail.com

1 Civil Engineering Department, Beykent University, Istanbul, Turkey

2 Kelebekia Sinpas S/7, Sancaktepe, Istanbul, Turkey 